\title{
Epidemiological features of subarachnoid and cerebral haemorrhages
}

\author{
S. TALBOT \\ M.B., B.S., M.R.C.P. \\ Pathology Department, Sheffield Royal Infirmary and Department of Forensic Medicine, \\ Sheffield University
}

\begin{abstract}
Summary
A study of coroner's necropsy statistics showed that subarachnoid and cerebral haemorrhage were important causes of sudden death in the community. There were more sudden deaths due to cerebral haemorrhage in women than in men but this was due to the increasing frequency of this condition with age and the sexes were equally affected if standardized mortality rates were calculated. Comparison with a study of hospital necropsy statistics showed that the latter was a selected group, elderly patients (predominantly women) being found less frequently. Deaths due to subarachnoid haemorrhage occurred as commonly in men as in women, but were rare over the age of 60 years. This fact probably accounted for the similar epidemiology of these fatal cases in the hospital and the community.

There was no significant seasonal variation in the death rate due to either cerebral or subarachnoid haemorrhage if surgically treated cases were excluded.

The mortality of both these conditions was highest at the onset and rapidly decreased. A secondary rise in mortality due to subarachnoid haemorrhage occurred between the sixth and eighth days after the onset in the hospital group. The length of survival before treatment is an important prognostic factor and must be known before the effect of treatment can be assessed.
\end{abstract}

\section{Introduction}

The epidemiology of any condition may differ in the community from that in hospital. In diseases with a sudden onset and a high early mortality the hospital cases represent the survivors, and the community deaths are usually sudden. The clinical picture of hospital cases will therefore be influenced by the admitting policy of the region, speed of transport to hospital, and the geographical distribution of facilities. In any study of the epidemiology of subarachnoid and cerebral haemorrhage both community and hospital groups must be included.

Studies of such conditions in the community are limited by the difficulties of diagnosis. However, patients with subarachnoid and cerebral haemorrhage are rarely supervised at home. Therefore, the prevalence of these conditions in the community is probably similar to their death rates. The object of the present study was to analyse the difference between cases dying of subarachnoid and cerebral haemorrhage in the community and in hospital. In particular the age and sex of these cases and the duration of the diseases were compared.

Seasonal variation of death rates due to aortic aneurysm (Talbot \& Langman, 1972) may be a feature of all macroscopic and microscopic aneurysmal rupture. Therefore, the seasonal variations of berry aneurysmal rupture (subarachnoid haemorrhage) and non-aneurysmal cerebral haemorrhage were investigated. (The latter condition is frequently due to microscopic aneurysmal rupture; Cole $\& 8$ Yates (1967).) Complicating conditions such as pneumonia may produce a seasonal variation of late deaths but cannot affect a group of sudden deaths In view of the difficulties of diagnosis only cases dying in the community or in hospital, on whom a necropsy was performed, were studied.

\section{Method}

Necropsy records from the Coroner's office, Sheffield, were examined for the years 1965 to 1971 inclusive. They were classified into haemorrhages due to berry aneurysmal rupture and haemorrhages in which the bleeding point was not found. Since the former were usually subarachnoid haemorrhages and the latter were usually cerebral haemorrhages, these names will subsequently be used. If there was a systemic cause for bleeding, e.g. thrombocytopenia, or an angioma or neoplasm, these cases were excluded.

The date of death (or the presumed date of the haemorrhage if these dates were clearly different), the age and sex, the site of the aneurysm(s) and the presence of cardiomegaly (Zeek, 1942) were noted. Only community deaths were studied and cases admitted to hospital who were subsequently referred to the coroner were excluded from this analysis.

These cases were compared with a hospital group of cases at the Sheffield Royal Infirmary collected similarly from necropsy records. In addition, information was obtained of the time from the onset of 
symptoms to death, when possible, and whether there was operative intervention. For a comparable number of patients it was necessary to study hospital necropsy records for an 11-yr period (1960-70 inclusive).

\section{Results}

There were 336 cases in the community group ( $3.2 \%$ of necropsies). Nineteen cases were excluded because the haemorrhage was an incidental finding to to the causes of death. Of the remaining 188 persons with cerebral haemorrhage, there were seventy-four men and 114 women $(1: 1.5)$ and of the 129 persons with subarachnoid haemorrhage there were fifty-three men and seventy-six women $(1: 1 \cdot 4)$. Death occurred most frequently in men between 51 and 60 years of age and in women from 41 to 50 years of age. Cerebral haemorrhage occurred a decade earlier (Table 1). In the hospital group there were eightyseven men and eighty-nine women with subarachnoid haemorrhage. Their average age was slightly lower than in the community group. There were sixty-two men and seventy-nine women with cerebral haemorrhage. The usual age at death was at least 10 years less than that of the community group. In general, hospital cases had a wider range of ages, and young men and women below 40 years of age were rarely found in the community group (Table 2).
The seasonal variation of sudden and hospital deaths is shown in Table 3. (Five cases of sudden death due to subarachnoid haemorrhage were excluded because of failure to record the date of death.) There was no significant seasonal variation for any group, and both sexes were similarly affected. In fact the inclusion of post-operative deaths did not affect the figures, though separately these cases showed variation $\left(\chi^{2}=8.5, P<0.01\right)$. Cerebral thrombosis was an infrequent diagnosis in the community group and did not show seasonal variation, but in the hospital group there was an increased death rate in the winter due to complicating chest infections.

Cardiomegaly was frequently found in association with cerebral and subarachnoid haemorrhage but there was no significant difference between the groups. The mean heart weight of the cases of cerebral haemorrhage was $470.0 \mathrm{~g}$ for the men and $394.7 \mathrm{~g}$ for the women in the community group and 463.6 and $382 \mathrm{~g}$ respectively in the hospital group. The mean heart weights of the cases of subarachnoid haemorrhage were $433.6 \mathrm{~g}$ for men and $397.9 \mathrm{~g}$ for women in the community group and $417.0 \mathrm{~g}$ and $399.1 \mathrm{~g}$ respectively in the hospital group.

The interval from symptoms (and thus the onset of haemorrhage) to death due to subarachnoid haemorrhage is shown in Fig. 1 and for cerebral haemorrhage similar figures are shown in Fig. 2.

TABLE 1. The age groups of fatal cases of subarachnoid haemorrhage and cerebral haemorrhage in the community group (ten cases excluded)

\begin{tabular}{|c|c|c|c|c|c|c|}
\hline \multirow[b]{2}{*}{ Age groups (years) } & \multicolumn{3}{|c|}{ Cerebral haemorrhage } & \multicolumn{3}{|c|}{ Subarachnoid haemorrhage } \\
\hline & Men & Women & Total & Men & Women & Total \\
\hline $\begin{array}{c}\text { Up to } 30 \\
31-40 \\
41-50 \\
51-60 \\
61-70 \\
71-80 \\
81-95 \\
\text { Mean age }\end{array}$ & $\begin{array}{c}1 \\
2 \\
7 \\
11 \\
27 \\
19 \\
7 \\
66 \cdot 1\end{array}$ & $\begin{array}{l}1 \\
1 \\
9 \\
17 \\
26 \\
40 \\
20 \\
70 \cdot 7\end{array}$ & $\begin{array}{r}2 \\
3 \\
16 \\
28 \\
53 \\
59 \\
27\end{array}$ & $\begin{array}{c}5 \\
6 \\
13 \\
14 \\
12 \\
3 \\
0 \\
50 \cdot 7\end{array}$ & $\begin{array}{c}2 \\
9 \\
17 \\
15 \\
13 \\
4 \\
6 \\
57 \cdot 3\end{array}$ & $\begin{array}{r}7 \\
15 \\
30 \\
29 \\
25 \\
7 \\
6\end{array}$ \\
\hline Total & 74 & 114 & 188 & 53 & 66 & 119 \\
\hline
\end{tabular}

TABLE 2. The age groups of fatal cases of subarachnoid haemorrhage and cerebral haemorrhage in the hospital group (eleven cases excluded)

\begin{tabular}{|c|c|c|c|c|c|c|}
\hline \multirow[b]{2}{*}{ Age group (years) } & \multicolumn{3}{|c|}{ Cerebral haemorrhage } & \multicolumn{3}{|c|}{ Subarachnoid haemorrhage } \\
\hline & Men & Women & Total & Men & Women & Total \\
\hline $\begin{array}{c}\text { Up to } 30 \\
31-40 \\
41-50 \\
51-60 \\
61-70 \\
71-80 \\
81-95 \\
\text { Mean age }\end{array}$ & $\begin{array}{c}1 \\
2 \\
10 \\
19 \\
15 \\
6 \\
9 \\
59 \cdot 8\end{array}$ & $\begin{array}{c}1 \\
4 \\
7 \\
15 \\
26 \\
7 \\
9 \\
63 \cdot 0\end{array}$ & $\begin{array}{r}2 \\
6 \\
17 \\
34 \\
41 \\
13 \\
18\end{array}$ & $\begin{array}{c}11 \\
15 \\
24 \\
27 \\
8 \\
0 \\
1 \\
45 \cdot 2\end{array}$ & $\begin{array}{c}7 \\
14 \\
32 \\
28 \\
5 \\
2 \\
1 \\
47 \cdot 4\end{array}$ & $\begin{array}{r}18 \\
29 \\
56 \\
55 \\
13 \\
2 \\
2\end{array}$ \\
\hline Total & 62 & 69 & 131 & 86 & 89 & 175 \\
\hline
\end{tabular}


TABLE 3. The numbers of fatal cases of subarachnoid haemorrhage and cerebral haemorrhage in the community and in hospital in each month of the year

\begin{tabular}{|c|c|c|c|c|c|c|}
\hline & \multicolumn{3}{|c|}{ Cerebral haemorrhage } & \multicolumn{3}{|c|}{ Subarachnoid haemorrhage } \\
\hline & Hospital & Community & Total & Hospital & Community & Total \\
\hline January & 11 & 19 & 30 & 18 & 14 & 32 \\
\hline February & 11 & 16 & 27 & 18 & 11 & 29 \\
\hline March & 14 & 18 & 32 & 16 & 7 & 23 \\
\hline April & 12 & 19 & 31 & 17 & 10 & 27 \\
\hline May & 14 & 13 & 27 & 18 & 13 & 31 \\
\hline June & 6 & 9 & 15 & 9 & 4 & 13 \\
\hline July & 17 & 16 & 33 & 9 & 14 & 23 \\
\hline August & 8 & 19 & 27 & 17 & 10 & 27 \\
\hline September & 9 & 18 & 27 & 13 & 15 & 28 \\
\hline October & 8 & 12 & 20 & 7 & 4 & 11 \\
\hline November & 17 & 16 & 33 & 18 & 11 & 29 \\
\hline December & 14 & 13 & 27 & 16 & 11 & 27 \\
\hline Total & 141 & 188 & 329 & 176 & 124 & 300 \\
\hline \multicolumn{7}{|l|}{$\begin{array}{l}\text { Observed: } \\
\text { Number between }\end{array}$} \\
\hline $\begin{array}{c}\text { November and April } \\
\text { Expected number between }\end{array}$ & 79 & 101 & 180 & 103 & 64 & 167 \\
\hline $\begin{array}{l}\text { November and April } \\
\chi^{2}=\left(\underline{O-E)^{2}}\right.\end{array}$ & $\begin{array}{c}71 \\
0.9\end{array}$ & $\begin{array}{l}94 \\
0.52\end{array}$ & 165 & $\begin{array}{l}88 \\
2 \cdot 56\end{array}$ & $\begin{array}{l}62 \\
0.06\end{array}$ & 150 \\
\hline $\bar{E}$ & & & & & & \\
\hline$P$ & $<0.5$ & $<0.50$ & & $<0.30$ & $<0.95$ & \\
\hline
\end{tabular}

No comparable information could be found for the community cases although in general the onset of symptoms and death were on the same day. Operations were performed in twenty-seven men and thirty-two women with subarachnoid haemorrhage and one case of cerebral haemorrhage. Removal of these cases did not affect the shape of the mortality curves (Figs. 1 and 2), although the number of patients was lower. Complications were recorded in three patients with cerebral haemorrhage and ten patients with subarachnoid haemorrhage. Of the

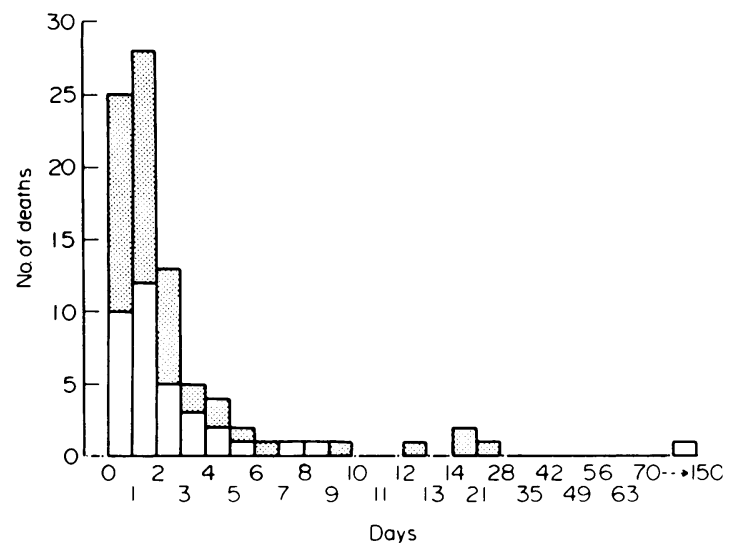

Fig. 1. The numbers of men (forty-five) and women (thirty-six) dying of cerebral haemorrhage expressed on the ordinate and the days after the onset of symptoms at which death occurred expressed on the abscissa. Open columns, females; stippled columns, males.

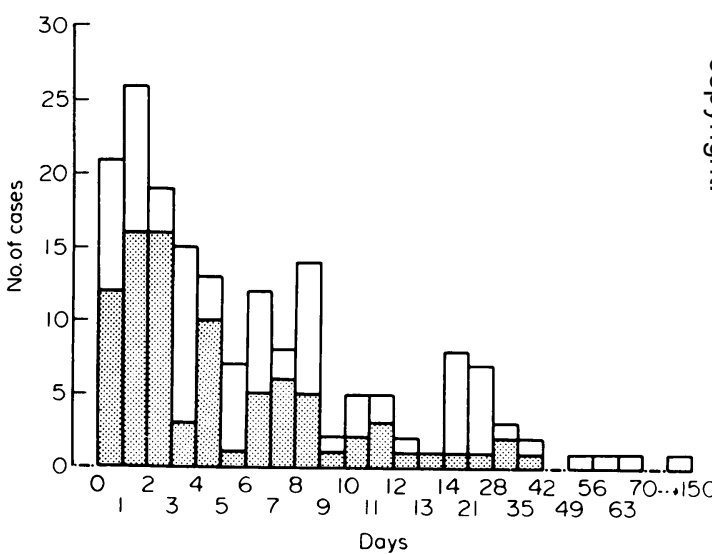

FIG. 2. The numbers of men (eighty-seven) and women (eighty-seven) dying of subarachnoid haemorrhage in hospital expressed on the ordinate and the days after the onset of symptoms at which death occurred expressed on the abscissa. (This includes operative cases.) Open columns, female; stippled columns, males.

latter there were seven cases with pulmonary emboli. These factors did not seem to have affected survival significantly.

There were no differences in the age and sex distribution for different locations of cerebral haemorrhage and aneurysms and the presence of cerebral as well as subarachnoid haemorrhage due to ruptured aneurysm did not increase the chance of sudden death. There were no significant differences in the incidence of ruptured aneurysms at different sites 
between groups or sexes. Rupture was almost always of only one aneurysm although in two cases there were multiple ruptured aneurysms.

Cerebral haemorrhage in both groups was usually supratentorial but after combinations of these cases it became apparent that there was a preponderance of men with pontine haemorrhage $(13.2 \%$ of all men and $6.7 \%$ of women with cerebral haemorrhage).

\section{Discussion}

Death from cerebral haemorrhage was more common than death from subarachnoid haemorrhage in a community study but the reverse applied in a hospital study. Both men and women in the community were older at death, particularly women, probably because age was an important factor influencing hospital admission. Standardized mortality rates were calculated for these studies and showed that for men in both groups and women in the hospital group with subarachnoid haemorrhage, the mortality rate rose up to 60 years of age and then remained constant. These findings confirm those of Carmichael (1950) who found that the incidence of cerebral aneurysm in hospital necropsies rose to a peak in the 50-60 age group and when corrected for the population structure remained the same. This is typical of a congenital condition whose time of rupture is determined by extrinsic factors. Hypertension accelerates rupture (and probably formation) of aneurysms, and the majority are found in patients with cardiomegaly. In the elderly, cardiomegaly was less frequently found in association with ruptured berry aneurysm.

The Registrar General's Hospital In-patients Enquiry (1964) provides information as to the prevalence of these conditions in hospital but there is no information of comparable accuracy for domiciliary practice. From this study at least $39 / 1,000,000$ of the population die of cerebral haemorrhage each year and at least $28 / 1,000,000$ of subarachnoid haemorrhage each year in domiciliary practice. In the community group subarachnoid and cerebral haemorrhage occurred more often in women but standardized mortality rates showed that this was because of the excess of elderly women in the community. Cerebral haemorrhage continued to increase throughout life, but elderly women with this condition were not represented in hospital necropsies.

Turnbull (1908) described the pathology of berry aneurysms. Middle cerebral aneurysms form the majority and in $40 \%$ of cases aneurysms are multiple. There were no significant differences in the prevalence of different ruptured aneurysms in this study although anterior cerebral and communicating aneurysms were the commonest type in the community group, unlike the hospital group. Walton
(1956) described the natural history of subarachnoid haemorrhage in hospital patients. When due to aneurysm it usually occurs in the fourth, fifth and sixth decades (Brain and Walton, 1969) and only $40 \%$ survive their first haemorrhage.

In this study it was apparent that there was a greater variation in the age of women than of men with either condition and this may be due to the epidemiology of hypertension. Cerebral haemorrhage may be due to rupture of micro-aneurysms which occur in hypertensive patients. This type of aneurysm is distinct from the congenital berry aneurysm that usually produces subarachnoid haemorrhage. These micro-aneurysms occur to an equal extent in either sex and increase in frequency throughout life so that their natural history clearly relates to that of the majority of cases of cerebral haemorrhage.

This study showed an insignificant seasonal variation in mortality for either cerebral or subarachnoid haemorrhage, unlike the results from death certification. [Registrar General's Hospital In-Patient Enquiry (1964), Takahashi et al. (1957) and Whylie (1962).] Complicating factors such as pneumonia might cause seasonal variation such as was found for hospital cases of cerebral thrombosis. This study of sudden deaths eliminated these factors. Talbot \& Langman (1972) found that there was seasonal variation of ruptured saccular aneurysm and dissecting aneurysm in a group of sudden deaths, and other vascular disorders such as bleeding peptic ulcer (Breen \& Grace, 1962) and ischaemic heart disease (Dunnigan, Harland \& Fyfe, 1970) have also been found to have a seasonal incidence. In view of the seasonal variation of blood pressure (Rose, 1961) and the association of cerebral and subarachnoid haemorrhage with hypertension, patients with significant cardiomegaly [ $>400 \mathrm{~g}$ heart weight and $>350 \mathrm{~g}$ heart weight for women (Cole \& Yates, 1967)] were separated but these cases also did not show any significant seasonal variation.

The most important difference between the community and hospital groups was in the time from symptoms to death. The onset of symptoms is usually clear-cut and reflects the time of the haemorrhage. Operation seemed to have little effect on this interval although survival may have improved. In the community group there were few symptoms and death seemed to be sudden. Therefore, extrapolation of the deaths on the first day upwards in Figs. 1 and 2 , could be made if these groups were combined. This rapid decrease in mortality with time is found in many vascular disorders, myocardial infarction (Smyllie et al., 1973), pulmonary embolism (Gorham, 1961) and dissecting and saccular aortic aneurysm (Talbot \& Langman, 1972). As with pulmonary embolism, recurrences disturb the progressive drop. This finding may make a difference of more 
than $50 \%$ in mortality statistics if admission is delayed by 2 days from the onset and this must be considered if the effect of treatment is being investigated.

Over the short period considered no confirmation was obtained of the postulated decrease in the incidence of fatal cerebral haemorrhage (Yates, 1964; Krueger et al., 1967). However the only necropsy evidence cited did not show a significant change and the increase in the diagnosis of cerebral thrombosis and the decrease in the diagnosis of cerebral haemorrhage may be due to fashion and more careful necropsy examination.

\section{Acknowledgments}

I am grateful for the help of Dr Kennedy and Dr Timperley of the Department of Pathology, Sheffield Royal Infirmary and to Dr A. Usher of the Department of Forensic Medicine, University of Sheffield for his advice, and allowing me to examine Coroner's necropsy records.

\section{References}

Brain, LoRd \& Walton, J.N. (1969) Diseases of the Nervous System, 7th edn, p. 315. Oxford University Press, London.

Breen, F.J. \& Grace, W.J. (1962) Bleeding peptic ulcer. Seasonal variation. American Journal of Digestive Diseases, $7,727$.

CARMichael, R. (1950) The pathogenesis of non-inflamatory cerebral aneurysms. Journal of Pathology and Bacteriology, 62, 1.

Cole, F.M. \& YATES, P.O. (1967) The occurrence and significance of intracerebral microaneurysms. Journal of Pathology and Bacteriology, 93, 2, 393.

Dunningan, M.G., Harland, W.A. \& Fyfe, T. (1970) Seasonal incidence and mortality of ischaemic heart disease. Lancet, ii, 793.
GorhaM, L.W. (1961) A study of pulmonary embolism. Archives of Internal Medicine, 108, 8.

Krueger, D.E., Williams, J.L. \& Paffenbarger, R.S. (1967) Trends in death rates from cerebrovascular disease in Memphis, Tennessee. 1920-60. Journal of Chronic Diseases, 19, 1165.

Puffer, R.R. \& Griffith, G.W. (1967) Patterns of Urban Mortality (Report of an Inter-American Investigation of Mortality). Pan American Health Organization, Washington.

Rose, G. (1961) Seasonal variation of blood pressure in man. Nature, 189, 235.

Sharnoff, J.G., Rosenberg, N. \& Mistica, B.A. (1963) Seasonal variation in fatal thromboembolism and its higher incidence in the surgical patient. Surgery, Gynaecology and Obstetrics, 116, 11.

Smyllie, H.C., Taylor, M.P. \& Cunninghame-Green, R.A. (1973) Acute myocardial infarction in Doncaster. 1. Estimating the size of a coronary care unit. British Medical Journal, 1, 31.

Takahashi, E., Sasaki, N., TAKeda, J. \& Ito, H. (1957) The geographic distribution of cerebral haemorrhage and hypertension in Japan. Human Biology, 29, 139.

TALBOT, S. \& LANGMAN M.J.S. (1972) Epidemiological features of ruptured dissecting and saccular aortic aneurysms. Postgraduate Medical Journal, 48, 414.

TuRnbull, H.M. (1918) Intracranial aneurysms. Brain, 41, 50.

Walton, J.N. (1956) Subarachnoid Haemorrhage. E. \& S. Livingstone, Edinburgh and London.

Whylie, C.M. (1962) Cerebrovascular accident deaths in the United States and in England and Wales. Journal of Chronic Diseases, 15, 85.

YATES, P.O. (1964) A change in the pattern of cerebrovascular disease. Lancet, i, 65 .

ZEEK, P.M. (1942) Heart weight. Weight of normal human heart. Archives of Pathology, 34, 820. 